\title{
Abrigo de La Viña (La Manzaneda, Oviedo, Asturias). Estudio de sus grabados parietales*
}

\author{
The La Viña rock shelter (La Manzaneda, Oviedo, Asturias): a study of its rock engravings \begin{abstract}
Elsa Duarte Matías ${ }^{\mathrm{b}}$ y Gabriel Santos Delgado
\end{abstract} \\ María González-Pumariega Solís ${ }^{\mathrm{a}}$, Marco de la Rasilla Vives ${ }^{\mathrm{b}}$, David Santamaría Álvarez ${ }^{\mathrm{b}}$,
}

\section{RESUMEN}

Se presentan en este trabajo los grabados paleolíticos del abrigo de La Viña (La Manzaneda, Oviedo, Asturias). A partir de la fotogrametría realizada por J. Fortea a finales de la década de 1990, se documentan los grabados exteriores de surco profundo conservados en el gran frente parietal que protege el asentamiento. Se incluyen los dos horizontes gráficos: uno, auriñaciense, no figurativo y anicónico; el otro, graveto-solutrense, que incorpora la figura animal, con un dominio mayoritario de la cierva. Este dispositivo parietal se adapta a las convenciones técnicas, formales y temáticas repetidas a lo largo de la cuenca media del río Nalón, con apenas excepciones.

\begin{abstract}
We present in this paper the Paleolithic engravings of La Viña rock shelter (La Manzaneda, Oviedo, Asturias). Using the photogrammetry made by J. Fortea at the end of the 1990's, we document the rock engravings conserved along the rock front that protects the settlement. Two cultural horizons are included: the first one, Aurignacian, is non-figurative and aniconic; the second one, Gravettian-Solutrean, includes animal figures, mostly female deer. This parietal group conforms, almost without exception, to
\end{abstract}

the general graphic conventions repeated along the Nalon river basin.

Palabras clave: Arte rupestre; Grabados exteriores; Paleolítico superior; Península Ibérica; Región Cantábrica; Río Nalón; Fotogrametría.

Key words: Rock art; Rock engravings; Upper Paleolithic; Iberian Peninsula; Cantabrian Region; Nalón River; Photogrammetry.

\section{INTRODUCCIÓN}

La Viña no es el exponente más espectacular de los yacimientos con grabados parietales de la cuenca media del río Nalón (Asturias) sobre todo por el extenso deterioro sufrido por la pared del abrigo. Su excepcionalidad reside en reunir circunstancias que suelen darse por separado o con menor evidencia y riqueza: su situación geográfica óptima, su gran extensión, la potencia del yacimiento y un conjunto de grabados parcialmente tapados por el depósito arqueológico.

\footnotetext{
* Esta investigación está parcialmente vinculada al Proyecto MINECO2015-HAR2014-59183-P.

a Consejería de Educación y Cultura del Principado de Asturias. Apartado de correos 29. 33590 Colombres. Correo-e: maria.glez-pumariegasolis@asturias.org http://orcid.org/0000-0003-4628-9068.

b Área de Prehistoria, Dpto. de Historia. Facultad de Filosofía y Letras. Universidad de Oviedo. C/Tte. Alfonso Martínez s/n. 33011 Oviedo. Correos-e: mrasilla@uniovi.es http://orcid.org/0000-0002-5505-0625; santamariadavid@uniovi.es http://orcid.org/00000002-7200-5746; elduarma@gmail.com http://orcid.org/0000-0003-2767-7049.

c Dpto. de Ingeniería Cartográfica y del Terreno. Facultad de Ciencias. Universidad de Salamanca. Plaza de la Merced s/n. 37008 Salamanca. Correo-e: gsd@usal.es http://orcid.org/0000-0002-0355-7088.

Recibido 4-VIII-2016; aceptado 13-XII-2016.
} 
Fortea difundió sus investigaciones en La Viña en casi una veintena de publicaciones específicas y generales de ámbito regional, nacional e internacional (Fortea 1981, 1983, 1990a, 1990b, 1990c, 1992a, 1992b, 1994, 1995, 1996, 1999, 2000-2001, 2001, 2003, 2005, 2005-2006; Fortea y Rodríguez 2007; Barandiarán et al. 1996). Este trabajo, como los anteriores (González-Pumariega 2014; González-Pumariega et al. 2014, 2015), a partir de las bases dejadas por Fortea, pretende publicar aquello que su prematuro fallecimiento interrumpió.

\section{ABRIGO DE LA VIÑA. CONTEXTUALI- ZACIÓN}

El abrigo de La Viña está situado en la localidad de La Manzaneda (Oviedo), en la Asturias central. El abrigo, completamente exterior, se abre en la base de un gran frente calizo orientado hacia el S-SE a casi $100 \mathrm{~m}$ sobre el valle del río Nalón, en su margen derecha. Las coordenadas UTM30 (ETRS 89) son $\mathrm{X}=270726 \mathrm{~m} ; \mathrm{Y}=4799478 \mathrm{~m}$; $Z=292$ ms.n.m. (Fig. 1). Esta posición a media ladera permite un holgado dominio visual del paisaje circundante ${ }^{1} \mathrm{y}$, en visión opuesta, las grandes dimensiones del frente rocoso lo hacen visible en el entorno. Las excavaciones arqueológicas (19801996, Sectores Central y Occidental) aportaron una secuencia que abarca desde el Paleolítico Medio hasta el Holoceno (Santamaría et al. 2014) (Fig. 2).

El perfil basal del yacimiento va perdiendo cota de E a O (Fortea 1999): hay 2,35 m de diferencia entre el sustrato calizo de la covacha oriental y el sustrato de pizarra/arenisca del extremo occidental. La paulatina superposición de las ocupaciones humanas desde el Musteriense al Auriñaciense fue modificando el piso. Durante el Auriñaciense reciente se enrasa, aun manteniendo una ligera inclinación (Fortea 1995; Santamaría 2012). Su altura determinó las condiciones de habitabilidad del abrigo y la percepción de la pared,

\footnotetext{
1 Todo apunta a que la "cuenca visual" de La Viña publicada (Corchón et al. 2014: 230, Fig. 6 dcha.) se calculó desde la cima del monte de La Manzaneda, y no desde el abrigo propiamente dicho. En ese caso, las visuales al norte del río Nalón serían parcialmente inválidas.
}

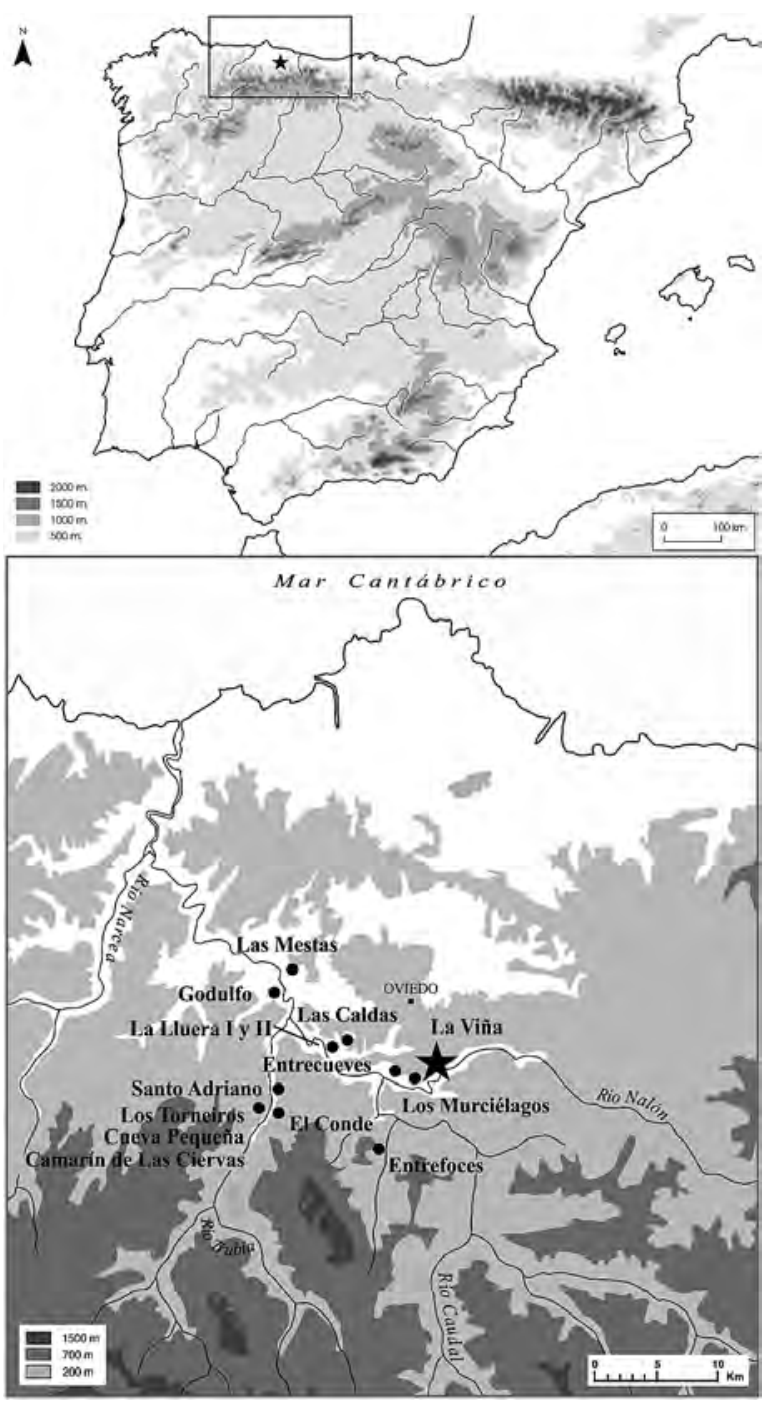

Fig. 1. Localización del abrigo de La Viña (La Manzaneda, Oviedo, Asturias) y de los yacimientos de la cuenca media del Nalón (según Fortea y Rodríguez 2007 modificado).

que adquiriría paulatinamente una continuidad visual más panorámica (González-Pumariega et al. 2015).

Los grabados se distribuyen a lo largo de ese frente parietal en completa exposición a la luz del día. Procesos de fracturación, erosión y reconstrucción lito-química distorsionan su lectura y limitan la interpretación global del conjunto, de su desarrollo y organización espacial, así como de su contenido temático; por ello, lo conservado solo permite una comprensión parcial de la topoiconografía del sitio. 

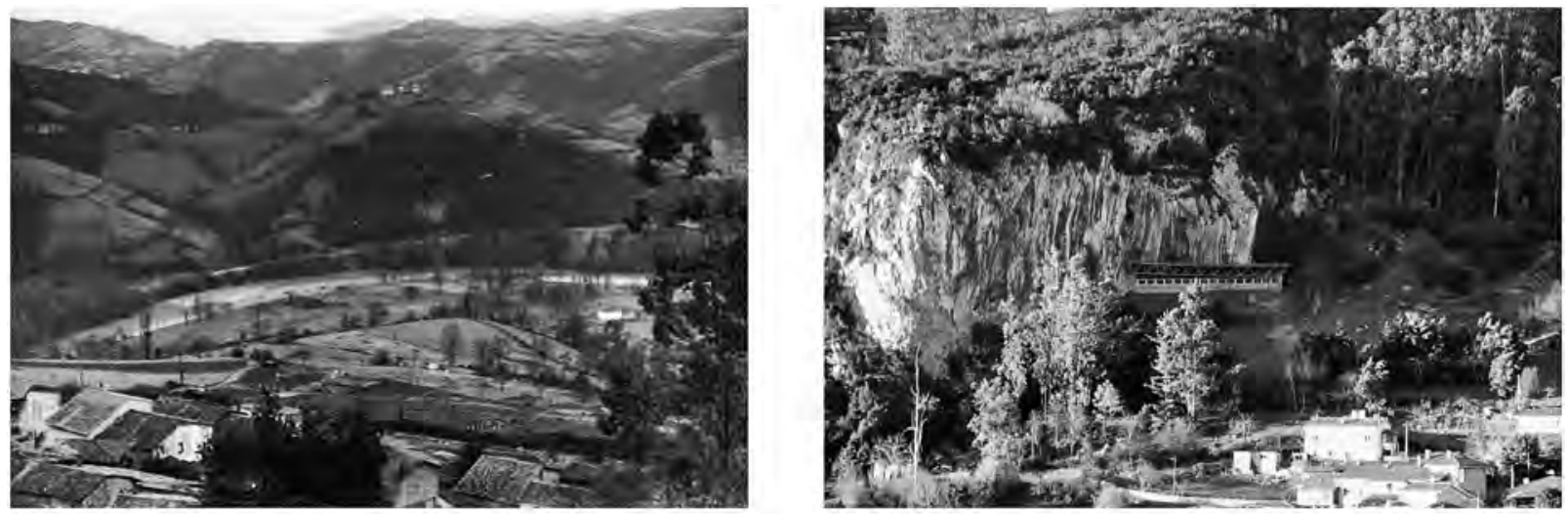

\section{- - Límite de la visera ..... Zonas con grabados Testigos adosados \\ - Cortes de referencia

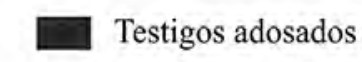

\section{S.C Sector central \\ S.O Sector occidental}

Curva $-0,75$ a $+99,25$ sobre río Nalón

Curvas de nivel bajo plano 0

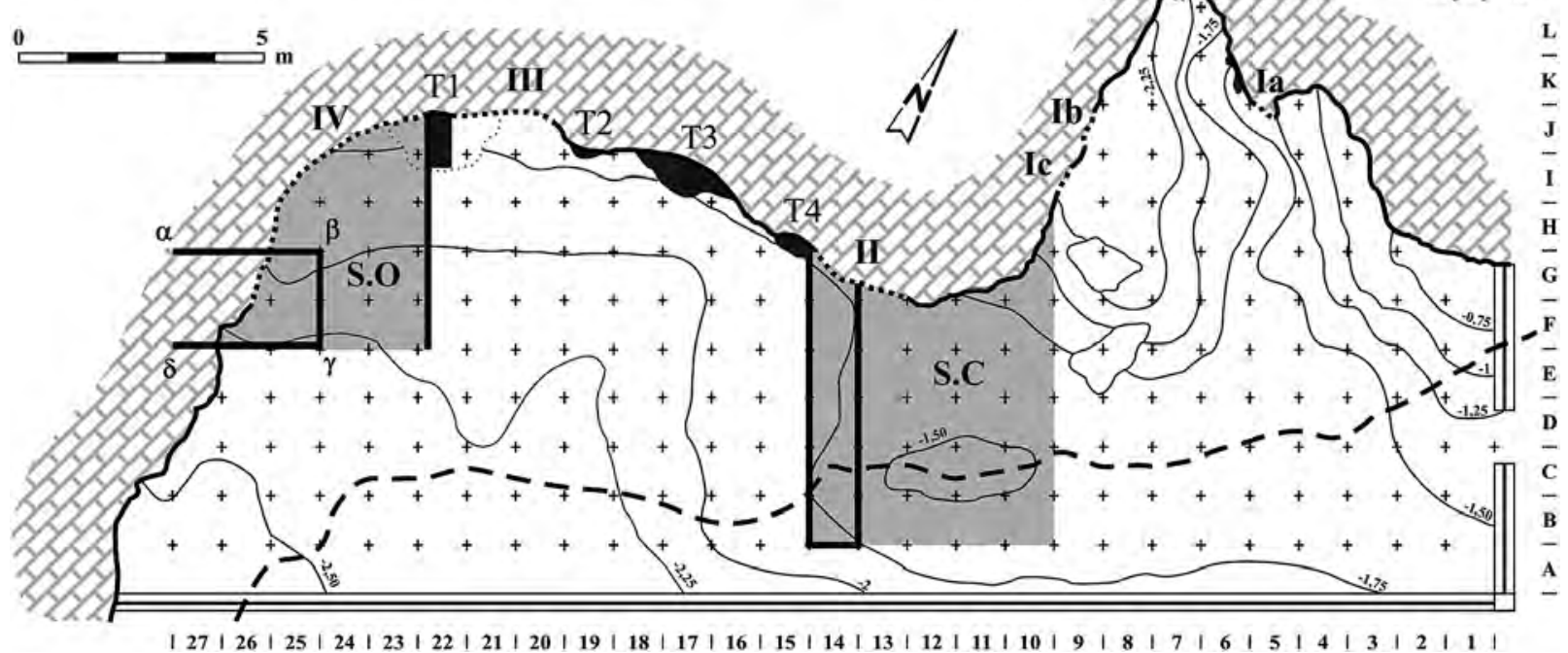

Fig. 2. Abrigo de La Viña. Arriba el valle del Nalón desde el yacimiento (izda.) y hacia el abrigo protegido (dcha.); abajo planta. Fotos M. Mallo y M. González-Pumariega, respectivamente.

En La Viña los dos horizontes artísticos (Fortea 1992a), individualizados en otros abrigos del Nalón, se suceden espacialmente sobre el plano vertical de la pared, ocupando alturas diferentes en relación con los suelos de ocupación. Los grabados conservados se distribuyen a lo largo de $20 \mathrm{~m}$, desde la covacha oriental hasta el extremo occidental del abrigo. Su grado de concentración espacial es variable. Las zonas donde la densidad es mayor quizá respondan a una organización simbólica de la pared pero, dada la importancia del deterioro del soporte, nuestra clasificación en zonas será fundamentalmente instrumental.

\section{DESCRIPCIÓN Y EVALUACIÓN DE LOS GRABADOS}

Presentamos la restitución fotogramétrica a escala 1:5 de las cuatro zonas (denominadas I a IV) donde se conservan grabados (Figs. 3-7), realizada a finales de la década de 1990 por la Empresa Cartografía Numérica S.L. (Cartonme) (Fortea 1999: 41).

Sobre esa base hemos hecho nuestro estudio, contrastando la lectura de entonces con la nuestra propia. Ratificamos la interpretación de Fortea salvo en unas pocas representaciones y 

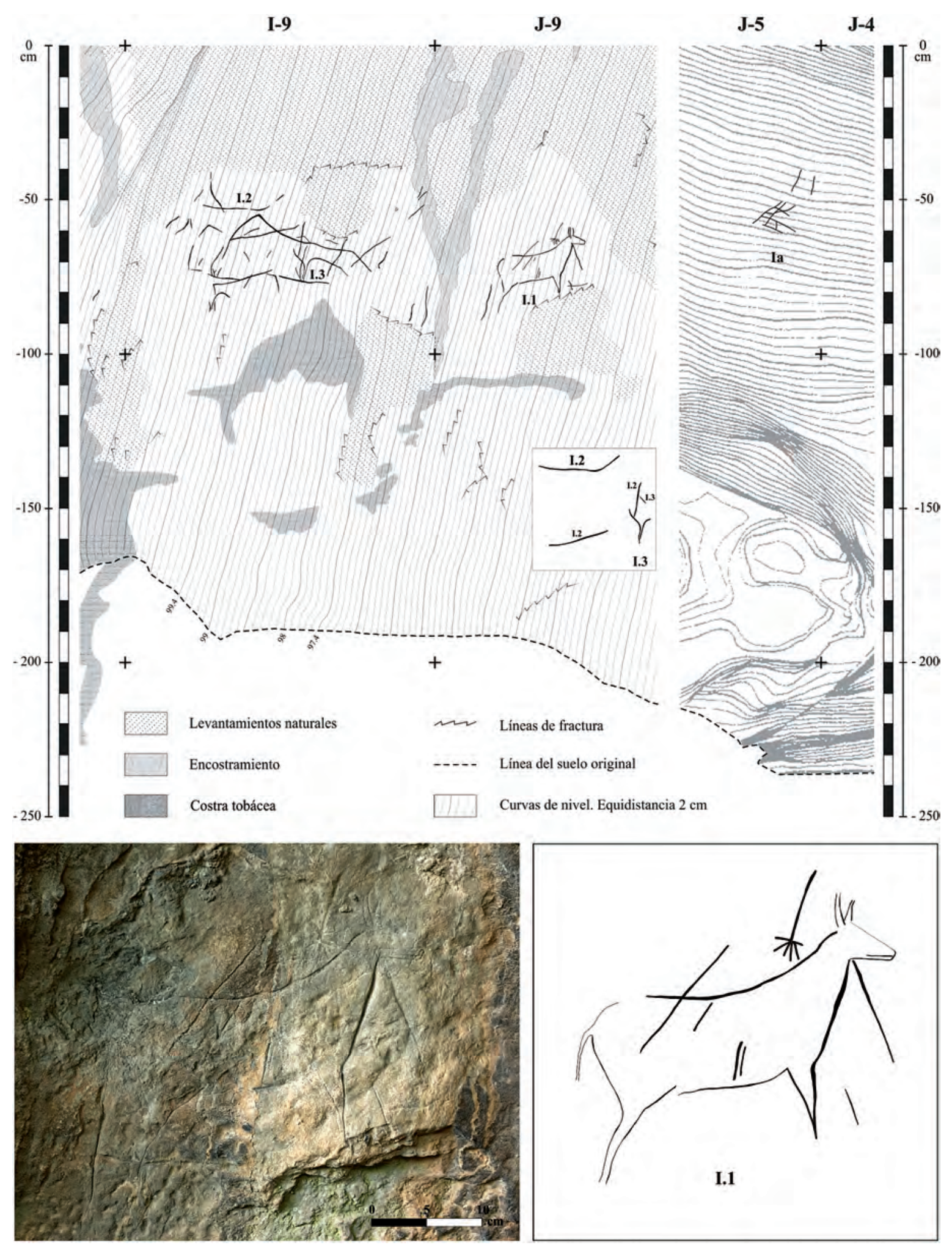

Fig. 3. Abrigo de La Viña. Arriba fotogrametría de las Zonas Ia, Ib y Ic (recuadradas las posibles figuras); abajo zoomorfo I.1 (calco según nuestra interpretación). Foto S. Ríos (en color en la edición electrónica). 


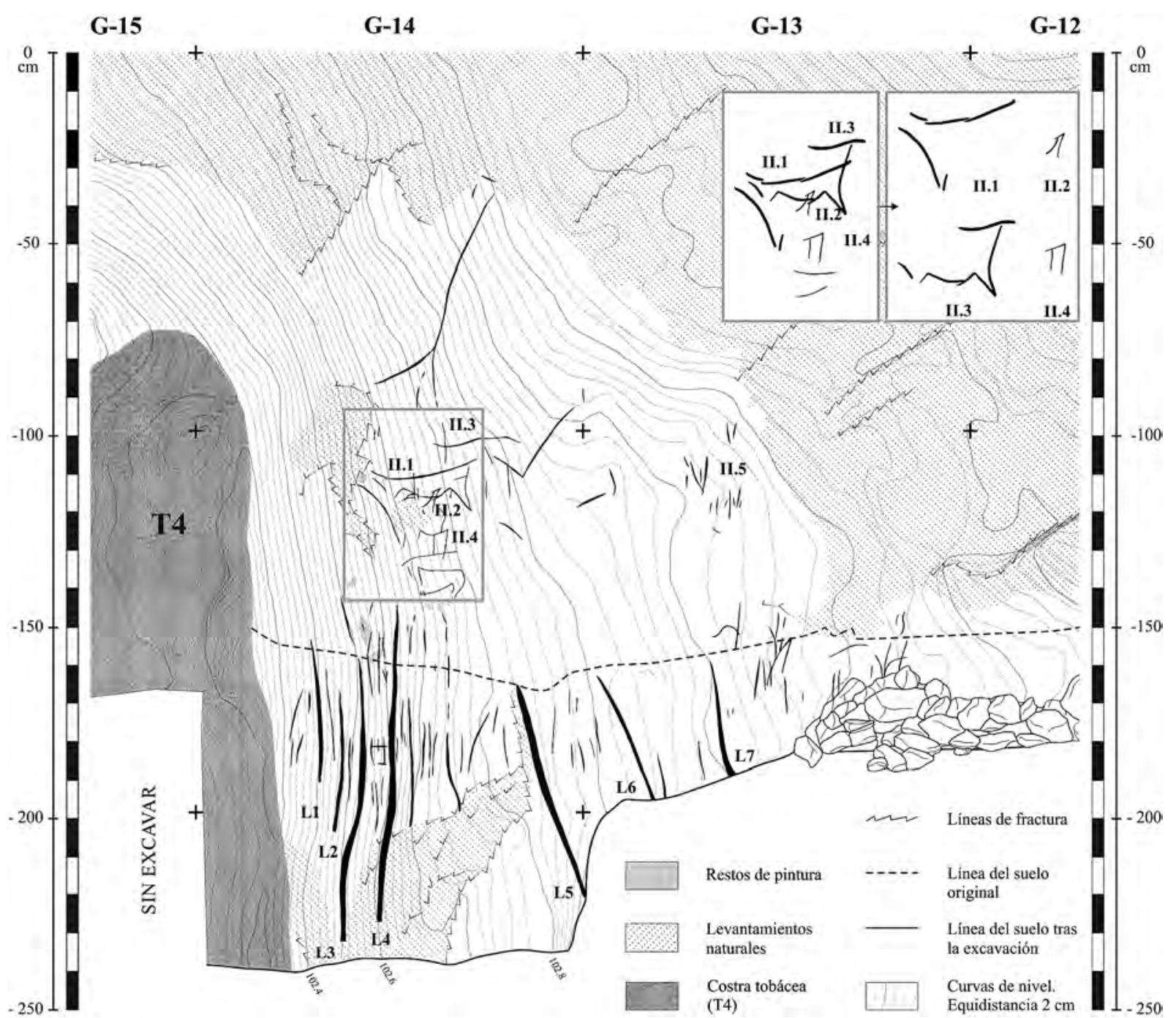

Fig. 4. Abrigo de La Viña. Fotogrametría de la Zona II con las figuras II.1 a II.4 desglosadas en recuadros (calco según nuestra interpretación).

trazos que hemos rectificado sobre las figuras (Figs. 3-5). Pero en el caso de aquellas representaciones más abigarradas de cierva que no están claramente destacadas en la fotogrametría (Fig. 7), nos referiremos a nuestro calco sobre fotografía (Fig. 8).

Cuando convenga precisar la ubicación de los grabados de cada zona recurriremos a la nomenclatura de la cuadrícula arqueológica (Fig. 2). Dadas las diferencias de altura del suelo actual del yacimiento aportaremos dos clases de datos: la altura ortométrica (coordenada Z), referida al nivel medio del mar en Alicante a partir del modelo geoide EGM08 (González-
Pumariega et al. 2015), y la cota respecto al nivel 0 arqueológico $(Z=293,38 \mathrm{~m})$. Estas últimas serán negativas porque el nivel 0 arqueológico es un plano cuadriculado aéreo coincidente con el máximo nivel sedimentario del abrigo (Fortea 1981; 1990a).

Las dimensiones de las figuras zoomorfas se refieren a la anchura por la altura en función de la inclusión ideal de la figura dentro de los límites de un rectángulo, salvo que se indiquen elementos anatómicos particulares. En caso de divergencia entre datos anteriormente publicados (GonzálezPumariega 2014; González-Pumariega et al. 2014, 2015) y los actuales, primarán estos últimos. 

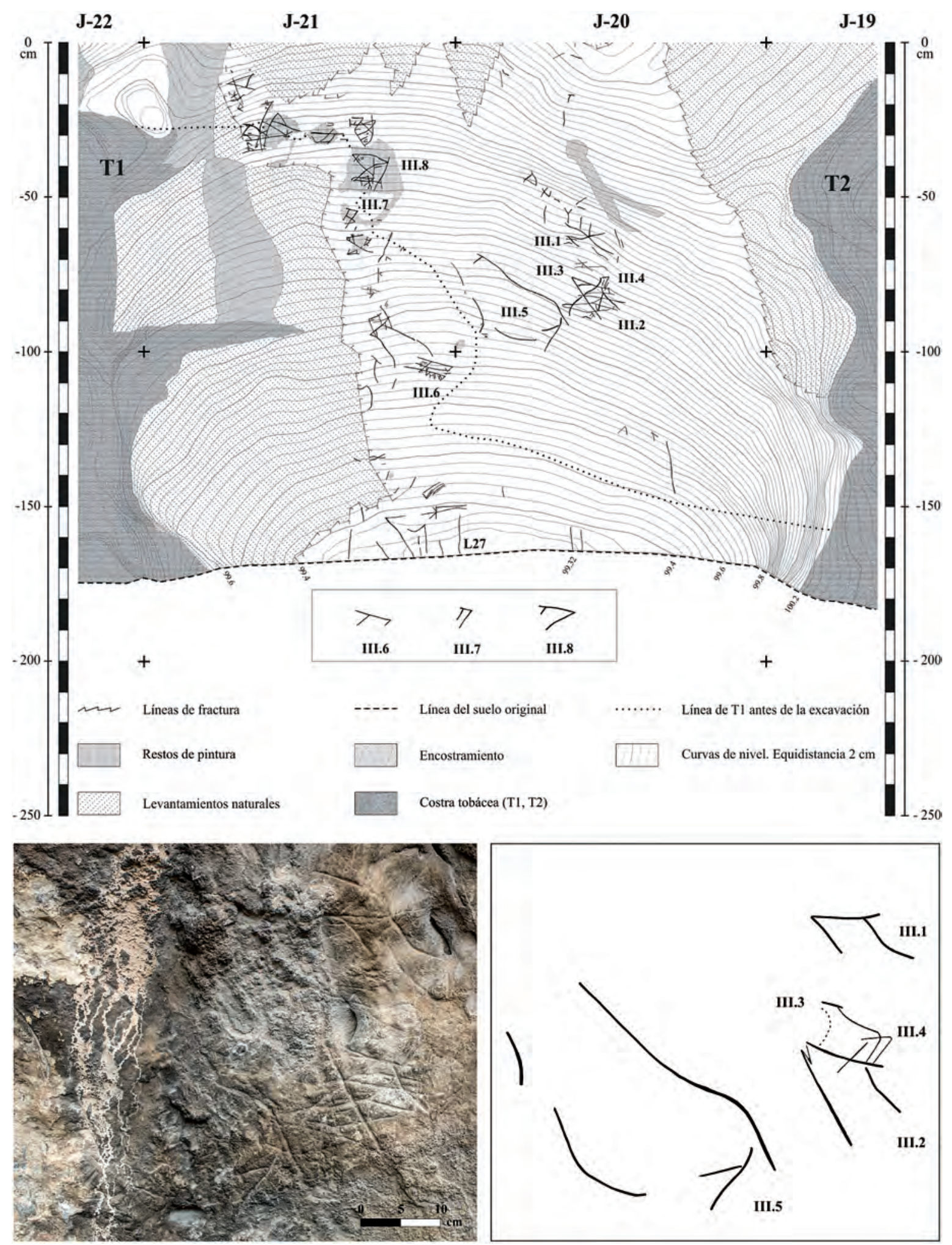

Fig. 5. Abrigo de La Viña, Zona III. Arriba fotogrametría con las figuras III.1 a III.8; abajo figuras III.1 a III.5 (calco según nuestra interpretación) Foto S. Ríos (en color en la edición electrónica). 


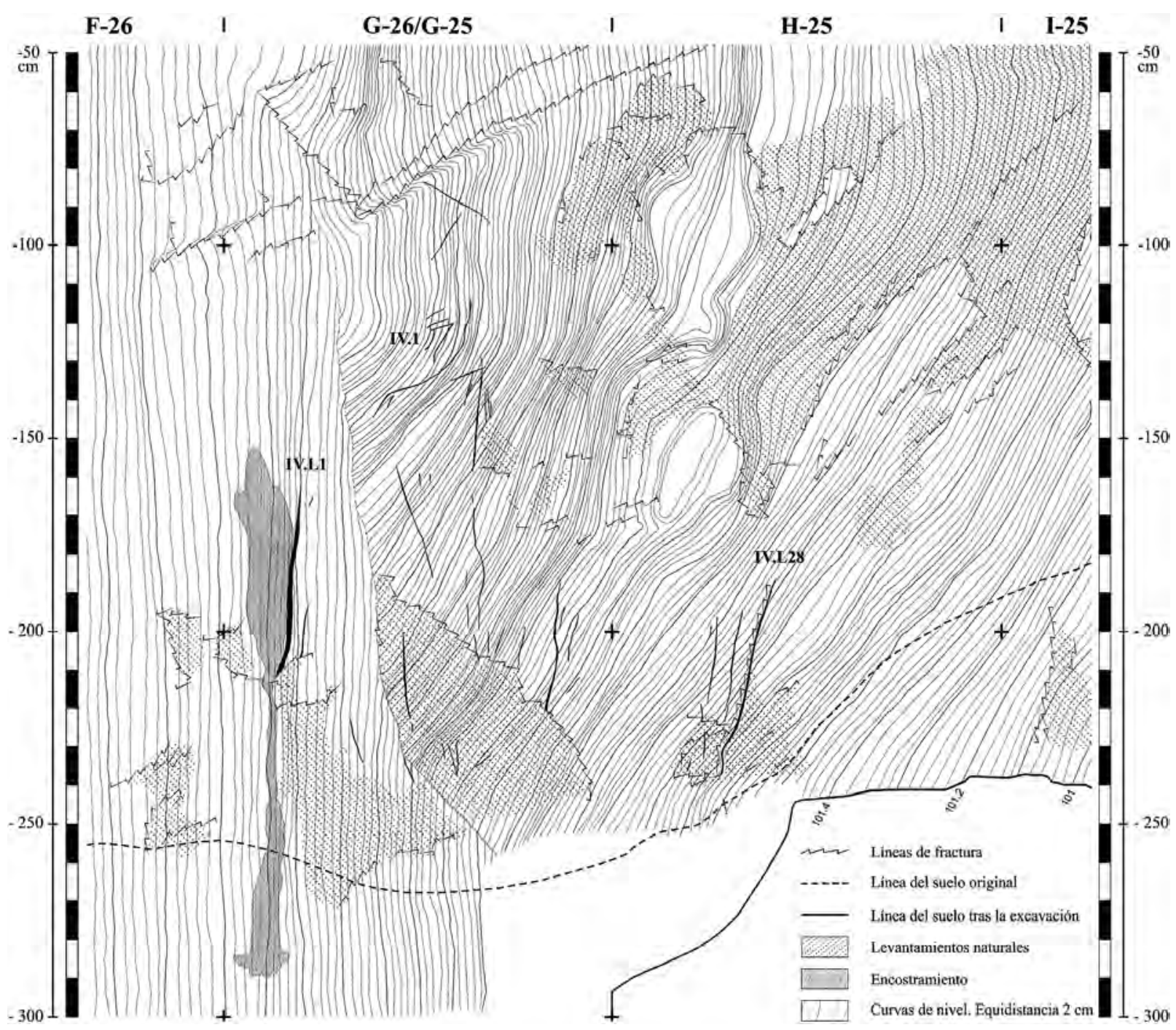

Fig. 6. Abrigo de La Viña. Fotogrametría de la Zona IV. Cuadros F-26, G-26/G-25, H-25 y parte de I-25.

\subsection{Zona I}

La Covacha es el espacio más abrigado del yacimiento pero solo conserva tres pequeñas áreas grabadas: en la pared oriental (Zona Ia) y en la occidental (Zonas Ib y Ic). Todas pertenecen al segundo horizonte gráfico (H2). Su altura ortométrica se corresponde con la cota general de este horizonte (siempre $+292 \mathrm{~m}$ ). Hemos documentado aquí 1 zoomorfo indeterminado (cérvido o caballo) y 2 probables ciervas (Fig. 3 ):

Ia: área irregular de pared de pequeñas dimensiones $(19$ x $40 \mathrm{~cm})$, situada a $170 \mathrm{~cm}$ del suelo actual del abrigo y cota ortométrica $\sim 293$ $\mathrm{m}$. Conserva un reducido grupo no figurativo de trazos lineales entrecruzados, anchos y profundos, muy erosionados.

Ib: zoomorfo I.1. en la pared occidental, cuadro J-9, a $179 \mathrm{~cm}$ del suelo actual respecto al lomo. Su altura ortométrica en ese punto anatómico es $292,86 \mathrm{~m}$ y $-0,52 \mathrm{~m}$ respecto al plano 0 de la excavación. Mide 30 x $26 \mathrm{~cm}$. Anatomía completa, representada en perfil derecho y posición horizontal. La figura está individualizada aunque sujeta a incertidumbre técnica y formal. La anatomía está completa pero el grabado no es

Trab. Prehist., 74, N. ${ }^{\circ}$ 2, julio-diciembre 2017, pp. 238-256, ISSN: 0082-5638 doi: $10.3989 /$ tp.2017.12193 


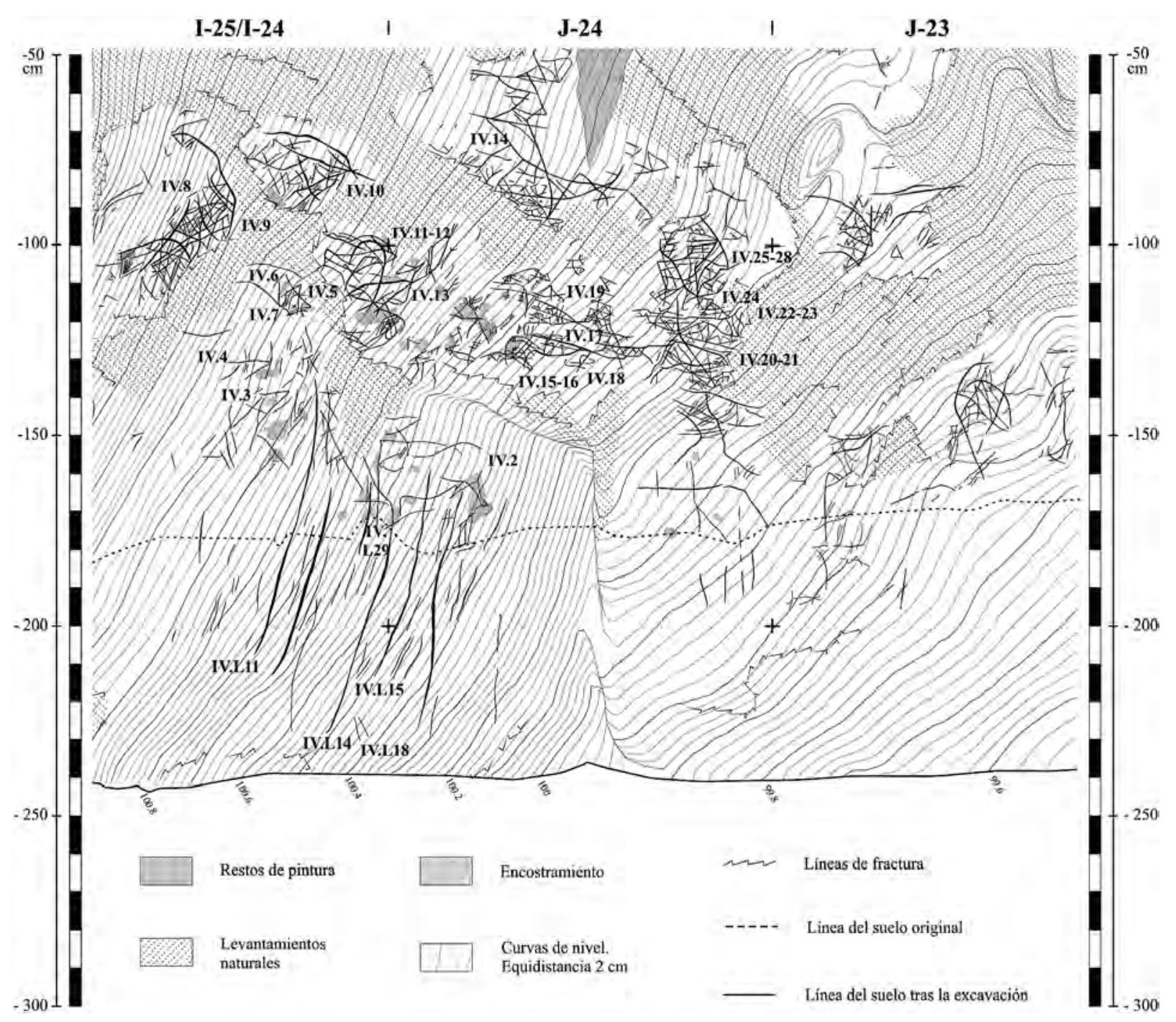

Fig. 7. Abrigo de La Viña. Fotogrametría de la Zona IV. Cuadros I-25 (continuación)/I-24, J-24 y J-23.

homogéneo. Las líneas que delimitan el lomo, el pecho y la pata delantera son más profundas que las que forman la cabeza y los cuartos traseros. Además, en la figura se reconocen elementos anatómicos que podrían corresponder a un cérvido y a un caballo por lo que la clasificamos como indeterminada. Fortea (1990a, 1994) la identificó como caballo sobre la base de su tratamiento individualizado (emblemático) y de su equivalencia topo-iconográfica con el caballo grabado en el Porche de La Lluera I, interpretación sin duda influenciada por el marco teórico de Leroi-Gourhan. Sin embargo, obviando los matices parciales de la anatomía, entendemos que su forma general se aproxima más a la de un cérvido que a la de un équido (Fig. 3 abajo). El análisis pormenorizado de cada elemento anatómico permite encontrar paralelos para ambas identificaciones, pero la figura se aleja de ambas especies si se compara con los estrictos convencionalismos gráficos de la cuenca media del Nalón. Ante esta ambigüedad formal, la disparidad técnica entre cabeza y cuartos traseros (Fortea no dibujó la cola, trazo que ha sido recientemente reconocido por G. Sauvet) y el resto del cuerpo nos parece importante, sobre todo porque abre la expectativa de una renovación de la figura, considerando los surcos más profundos coherentes con el contexto for- 

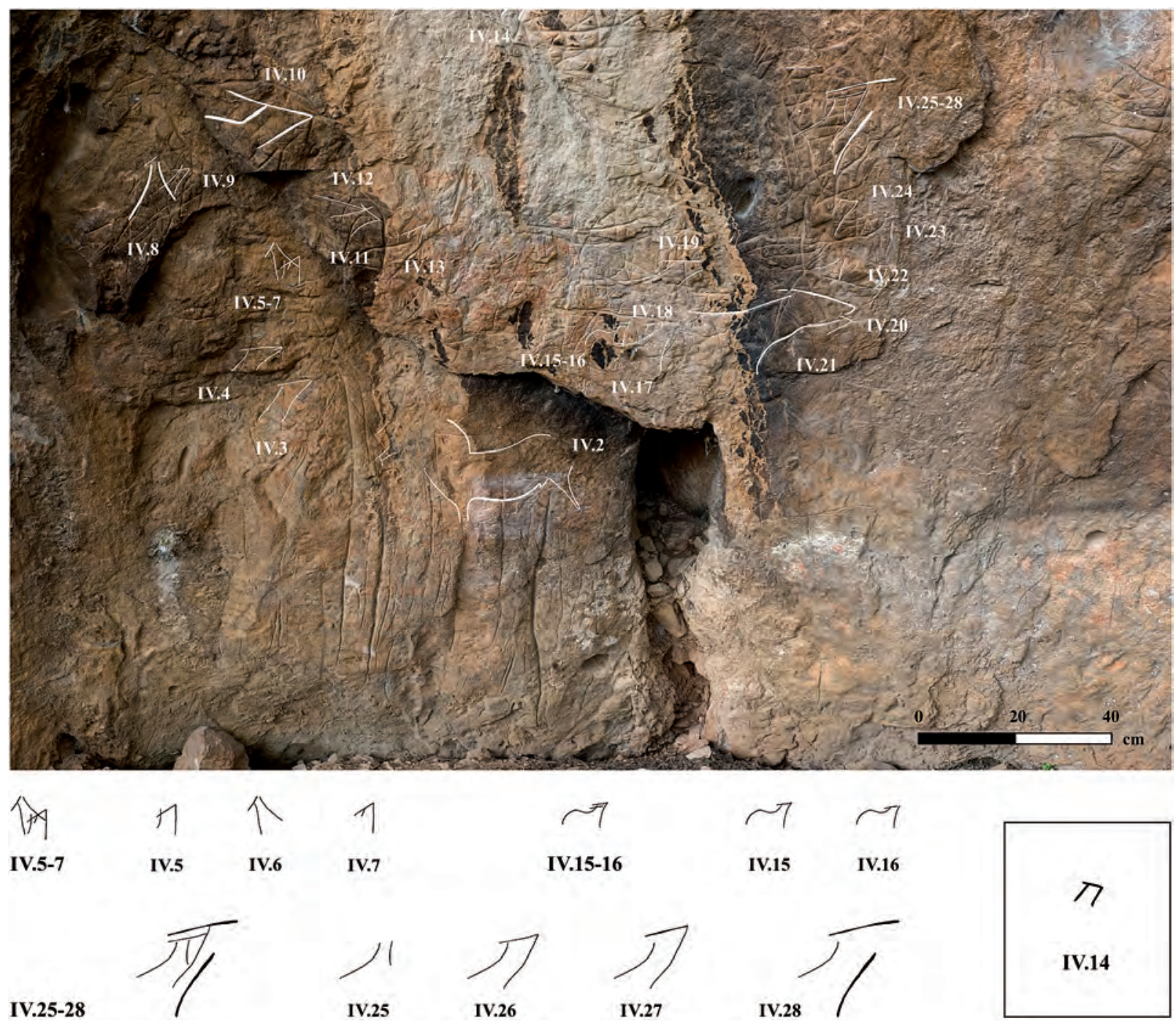

Fig. 8. Abrigo de La Viña. Zona IV. Grabados del horizonte gráfico H2. Arriba calcos sobre fotografía de S. Ríos (en color en la edición electrónica); abajo desglose de las ciervas superpuestas y calco completo de la cierva IV.14 recuadrado.

mal y técnico del $\mathrm{H} 2$ y el resto como añadidos posteriores. Así, su distanciamiento respecto a la ortodoxia formal de la cuenca del Nalón, donde no hay paralelos semejantes para representar cérvidos y caballos, podría explicarse remitiendo a un momento cultural probablemente posterior. Con todas las reservas, esta hipótesis nos parece más plausible que la variabilidad sincrónica amplia que propone González Sainz (1999; Aguirre y González Sainz 2011) para el contexto gráfico en el que nos encontramos, dada, sobre todo, la forma de representación de las orejas y la cola, completamente ajena al ámbito de los grabados profundos exteriores del Nalón. En el entorno del animal hay trazos lineales: dos en la garganta y el pecho; uno con extremo inferior desflecado en la nuca; varios en el vientre y el lomo. El más neto le atraviesa la grupa, aunque el sentido de la superposición no está claro.

Ic: grupo no figurativo de líneas curvas y rectas entrecruzadas, situado unos centímetros a la izquierda del lienzo anterior, en el cuadro I-9. Estos grabados ocupan un sector de la pared muy fracturado y erosionado de 76 x $48 \mathrm{~cm}$. Se encuentra entre 155 y $190 \mathrm{~cm}$ del suelo actual a la misma cota ortométrica que los otros dos paneles. 


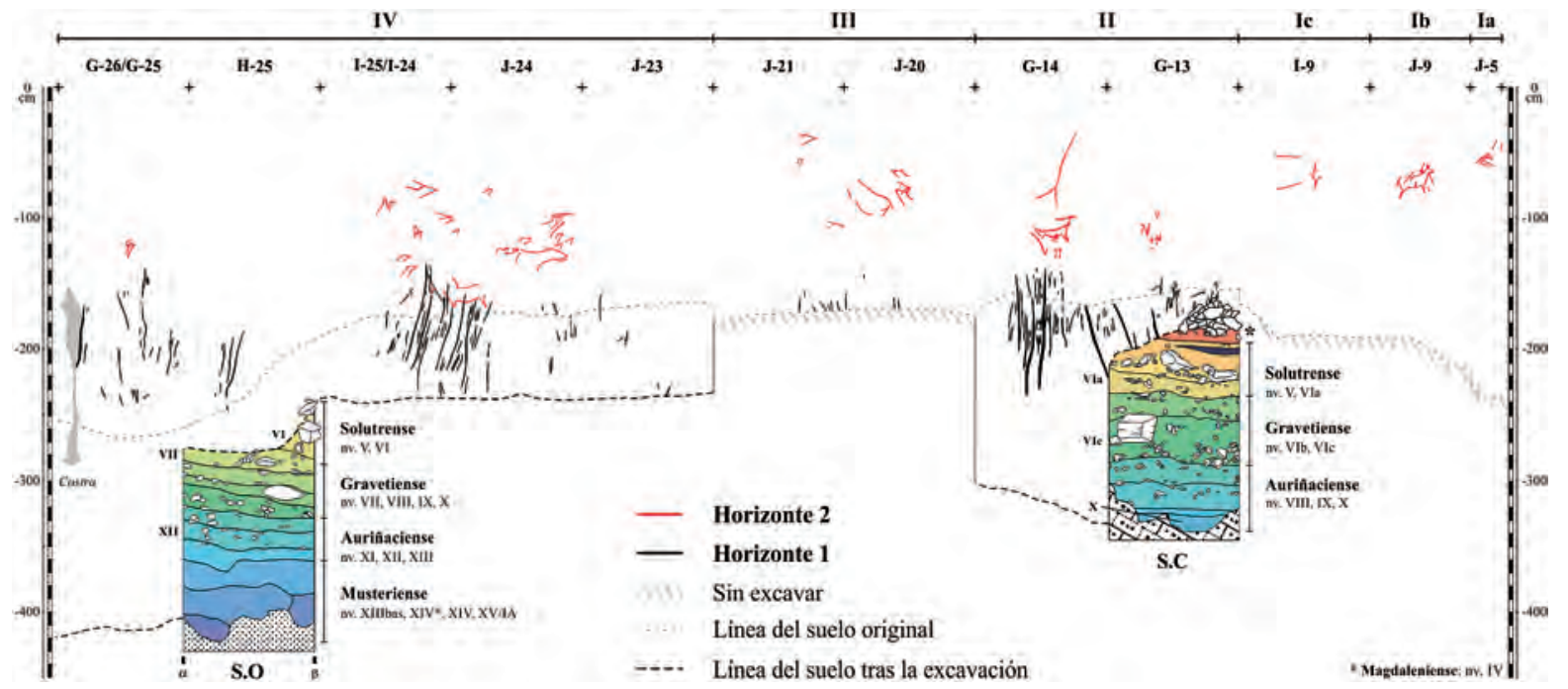

Fig. 9. Proyección de los grabados de los dos horizontes gráficos de La Viña a partir de la fotogrametría. La inclinación media del horizonte gráfico H2 (3,7\%) es coherente con la inclinación media de los niveles solutrenses y gravetienses (3-4\%). Nótese la diferencia del perfil basal en los Sectores Occidental (S.O) y Central (S.C) (en color en la edición electrónica).

Algunas líneas podrían corresponderse con segmentos anatómicos de cérvidos, pero su grado de deterioro impide reconocerlos con claridad. Tres trazos de técnica y escala semejantes podrían ser las líneas del lomo, pecho y vientre de un cérvido orientado a la derecha (I.2). Otras dos líneas parecen figurar una pata delantera y el pecho de una cierva en perfil izquierdo y podrían estar relacionadas, a su vez, con un tracito lineal cuya posición y características técnicas sugiere el arranque del cuello de esa misma figura (I.3) (Fig. 3 arriba recuadrada). Fortea (1994: 210) comparó esta última representación parcial con los grabados de una plaqueta proveniente del Gravetiense final de Isturitz (excavación de Saint-Périer), descritos como "contornos inacabados" por Leroi-Gourhan (1971: 355 y 434).

\subsection{Zona II (Fig. 4)}

Esta zona comprende los cuadros G-13 y G-14. En el cuadro G-14 los grabados quedaron por completo descubiertos al finalizar la excavación. En los cuadros G-13 a G-10 contiguos, la excavación se detuvo en el techo del Solutrense superior (Fortea 1990a, 1992a), por lo que la historia gráfica de la pared solo es visible en parte. Se do- cumentan aquí los dos horizontes gráficos. El H1 se desarrolla entre $-1,38 \mathrm{~m}$ y $-2,33 \mathrm{~m}$ de altura, respecto al nivel 0 arqueológico (coordenadas $Z=$ $292,00 \mathrm{~m}$ y $291,05 \mathrm{~m}$ respectivamente) y el H2 entre $-0,43 \mathrm{~m}$ y $-1,38 \mathrm{~m}$ (coordenadas $Z=292,95$ $\mathrm{m}$ y $292,00 \mathrm{~m}$ respectivamente). Es decir, en esta zona ambos horizontes coinciden sin solapamiento expreso en el punto $-1,38 \mathrm{~m}$, correspondiente a la parte superior de los grabados del $\mathrm{H} 1$ y a la inferior de los del $\mathrm{H} 2$.

El Primer Horizonte Gráfico (H1) está representado por trazos verticales regular y rítmicamente organizados. El ritmo principal lo marcan siete poderosos tajos de surco muy profundo, cuya inclinación parece adaptarse simétricamente a la morfología convexa de la pared. L1 a L4 están grabados en el plano izquierdo con desarrollo casi vertical y ligera inclinación hacia la derecha y L5 a L7 en el derecho con clara inclinación hacia la izquierda. L1 a L5, situados en G-14, están totalmente descubiertos, mientras que L6 y L7 continúan tapados en parte por el depósito estratigráfico de G-13 sobresaliendo 36 y $22 \mathrm{~cm}$ del suelo respectivamente. Aun afectadas por el lavado del agua y la fracturación de la pared, todas las líneas menos L5, conservan casi íntegramente el surco grabado, de sección en $\mathrm{V}$ y tendencia fusiforme. Son trazos que miden entre 41 y $90 \mathrm{~cm}$ de longitud, entre 1 y $2,5 \mathrm{~cm}$ de 
anchura y hasta $2 \mathrm{~cm}$ de profundidad. El trazo L5 está muy afectado por la rotura y descamación de la pared, por lo que solo conserva el fondo del surco. Entre estos siete tajos principales se intercalan, paralelos a ellos, numerosos trazos verticales, más cortos y menos profundos, manteniendo el criterio rítmico de distribución.

El Segundo Horizonte Gráfico (H2) comprende cuatro zoomorfos (3 cérvidos y 1 bovino) y trazos lineales no figurativos, algunos indeterminados y otros estructurados.

Zoomorfo acéfalo (II.1): es un posible cérvido orientado hacia la izquierda. Si tuvo cabeza es hoy inexistente por haber ahí una fractura; en todo caso, la abreviación formal de la figura (tres trazos lineales) es la característica del H2. La línea cérvico-dorsal es recta con suave curvatura hacia el cuello (mide $35 \mathrm{~cm}$ de nuca a grupa) y se grabó mediante un surco ancho y relativamente profundo. En el trazo se distinguen tres segmentos consecutivos (nuca, dorsal y lumbar) y dos interrupciones gráficas entre ellos. La continuidad gráfica de la línea se simula disponiendo ambos extremos del segmento dorsal en paralelo (no superpuestos, ni en continuidad neta) al extremo derecho del de la nuca y al izquierdo del segmento lumbar. Las características técnicas de la línea del pecho y de la pata delantera $(17 \mathrm{~cm})$ son idénticas a la anterior. En cambio, el trazo que delimita la cara posterior de la pata $(3 \mathrm{~cm})$ es algo menos profundo y más estrecho. Este zoomorfo se superpone a todos los trazos con los que se cruza.

Prótomo de cierva (II.2): es una pequeña y expresiva figura, inscrita en el cuerpo de la anterior y orientada hacia la derecha. Dentro del estereotipo clásico del Nalón, la línea del pecho es más larga que la del lomo: $5 \mathrm{~cm}$ de la nuca al final del lomo y $8 \mathrm{~cm}$ de la boca al final del pecho.

Posible bisonte orientado hacia la izquierda (II.3): su lectura es difícil por su deterioro y la ausencia casi total del tren delantero. De la línea cérvico-dorsal se conserva solo la zona lumbar, cuyo extremo derecho se prolonga a modo de cola erguida. La nalga es recta y ligeramente convexa. Tiene pata trasera en V. Definen el vientre dos trazos, con interrupción gráfica entre ellos: el del contorno posterior es ligeramente curvo y bifurcado en la zona del sexo y el del contorno anterior es recto. La pata delantera en $\mathrm{V}$ es más abierta que la trasera. Aun sin gran parte del lomo, pecho y cabeza, el desarrollo de la zona ventral y la pata delantera es mayor que el de los cuartos traseros, más cortos. Ello unido al trazado continuo y erguido de la cola (con probable inflexión posterior en ángulo recto) y al ímpetu que parece sugerir la disposición de las patas, nos inclina a identificarlo como bisonte. La línea posterior del vientre se cruza con el cuello de la cierva II. 2 en tres puntos (dos en el pecho y uno en la nuca de la cierva), sin embargo el sentido de la superposición no está claro. La nalga del bisonte está cortada por la grupa del cérvido II.1, que se le superpone nítidamente.

Cierva trilineal (II.4): aparece en perfil derecho. Es menos expresiva y más tosca que la II.2, pero identificable como tal.

Además de estas representaciones animales, se conservan en el sector de pared correspondiente al cuadro G-14 trazos lineales indeterminados que no responden a una ordenación figurativa, grabados en distinta orientación y tamaño y alguno de ellos es bastante largo. Destaca el que está situado algo más arriba del bovino, pues su extremo superior está a solo $-0,43 \mathrm{~m}$ del nivel 0 arqueológico, cota de grabado más alta en esta Zona II. En el sector de pared del cuadro G-13, hay también unos pocos tracitos lineales que Fortea (1990a: 66) describió como signos en V (II.5). Los que están grabados más abajo se encuentran a +46 $\mathrm{cm}$ del extremo superior del tajo L7, por tanto, inequívocamente dentro de la cota del H2. Estos trazos no siempre están desordenados y dispersos por la pared sino que, al menos en tres casos, tienden a la agrupación. El único que adopta con claridad forma en $\mathrm{V}$ con bisectriz tiene los dos trazos laterales que se unen en el vértice inferior más largos, anchos y profundos que la línea interior. A su derecha, un par de centímetros más arriba, hay dos trazos convergentes que no llegan a formar la V completa; y en una cota ligeramente más baja, un grupo de cuatro tracitos convergentes que tampoco llegan a cerrarse en un vértice común. Algún trazo más de características similares se lee en las inmediaciones de este y aquel. Entendemos estas agrupaciones, a pesar de sus diferencias, como versiones más o menos precisas de un mismo motivo gráfico. Están grabadas entre las cotas $-0,99 \mathrm{~m}$ y $-1,23 \mathrm{~m}$ respecto al 0 arqueológico. 


\subsection{Zona III}

Entre los grabados de las Zonas II y IV hay $8 \mathrm{~m}$ de pared extensamente afectada por los procesos geológicos de degradación que se observan en todo el frente parietal, aquí con huellas más rotundas que en las otras zonas. Se adosan a la pared cuatro masas amorfas de concreción calcárea (T1 a T4) (Fig. 2), que fueron limpiadas, raspadas y/o excavadas para intentar reconocer en ellas materiales de las fases de ocupación posteriores a las registradas en el suelo actual. Se intervino especialmente sobre el T1, excavando sus tres caras hasta transformarlo en una suerte de prisma tetragonal. A medida que se retiraban los sedimentos cementados a la pared iban apareciendo líneas grabadas pertenecientes al $\mathrm{H} 2$. $\mathrm{La}$ expectativa era verosímil dado que en el metro de pared sin concreción entre T1 y T2 (cuadro $\mathrm{J}-20$ ), se leían con claridad algunos trazos y representaciones figurativos propios de ese horizonte cultural. Todavía asoman del suelo algunos trazos lineales verticales sugeridores del H1. Esta zona se corresponde con los metros 20 y 21 (Fig.5).

Los indicios del Primer Horizonte Gráfico aparecen en el sector de pared del cuadro J-21 donde, a ras de suelo, hay una serie de seis cortos trazos lineales, dispuestos regularmente en abanico, que sobresalen unos $10 \mathrm{~cm}$ por encima del depósito estratigráfico. En el cuadro J-20 contiguo sobresalen 5-6 cm de otros dos trazos lineales. Todos ellos parecen corresponderse con el extremo superior de series lineales regularmente ordenadas del $\mathrm{H} 1$, aunque esta afirmación no será más que una conjetura mientras la pared no quede liberada del depósito arqueológico. El extremo superior de L27, la que más sobresale del suelo, está a $-1,57 \mathrm{~m}$ respecto al nivel 0 arqueológico (coordenada $Z=291,81 \mathrm{~m}$ ). La cota equivale a la de ciertas rayas de G-14 y a la de algunas de la Zona IV.

Las líneas conservadas pertenecientes con seguridad al Segundo Horizonte Gráfico se ubican entre las cotas ortométricas $293,29 \mathrm{~m}$ y $292,22 \mathrm{~m}$ (-0,09 $\mathrm{m}$ y $-1,16 \mathrm{~m}$ en relación al 0 arqueológico, respectivamente). Hemos identificado 7 figuras de cierva (4 seguras y 3 probables) y 1 zoomorfo indeterminado. En la pared correspondiente al cuadro J-20 se conservan algunos trazos lineales indeterminados y dispersos cercanos al nivel 0 arqueológico. Algo más abajo de estos hay más trazos dispersos, alguno tendente a lo figurativo, y una pequeña concentración de líneas entrecruzadas entre las que se entresacan varias ciervas ${ }^{2}$.

Cierva trilineal (III.1): en perfil izquierdo con surco ancho y profundo. No es una representación habilidosa pero consideramos que puede identificarse como tal. La mayor o menor corrección formal de las líneas responde al punto de vista desde el que se observa. La línea de la espalda es recta en la nuca curvándose para figurar la zona lumbar.

Cierva trilineal (III.2): en perfil izquierdo con surco ancho y profundo que se superpone nítidamente a todas las líneas que cruza, singularizándose frente a todas. Es una de las ciervas más visibles de La Viña. Al contrario que la anterior, es una representación virtuosa y también muy expresiva pues se representa mirando hacia arriba y con la boca abierta. Este efecto se logra evitando unir los extremos de las líneas frontal y mandibular y adaptándola perfectamente al microrrelieve de la pared sobre el que se realiza una corta incisión, limpia y precisa, que sugiere la comisura. En esta cabeza de cierva se emplea el estereotipo habitual aunque, al igual que la cierva III.1, la línea de la espalda no se traza recta, sino en ángulo, diferenciando la nuca del resto. Mide $4 \mathrm{~cm}$ desde el morro hasta el extremo de la oreja y $15 \mathrm{~cm}$ desde aquel hasta el extremo del pecho.

Cierva casi completa (III.3): en perfil izquierdo para adaptarla a la forma natural del soporte. Se sitúa en paralelo a la línea naso-frontal de la III.2, sobre la que se apoya, casi evocando la línea del suelo. Esta pequeña cierva, casi completa, responde al estereotipo habitual del Nalón, aunque con un carácter muy excepcional pues integra hábilmente la forma natural de la pared en la ejecución de la figura. Aprovecha el contorno curvo de una pequeña oquedad que se interpreta, sin retoque alguno, como la línea del pecho, en recorrido continuo desde la boca hasta la pata delantera. El resto del cuerpo se añade a su derecha sobre el plano contiguo de la pared, grabando dos trazos: la línea naso-frontal, recta, de $3 \mathrm{~cm}$ y la línea del lomo, prolongada

\footnotetext{
${ }^{2}$ Fortea nunca publicó los grabados de la Zona III; sin embargo, Corchón (2014: 30-31) ha publicado recientemente una de sus fotografías, identificando erróneamente tanto la ubicación del lienzo ("panel del covacho") como los grabados que se muestran ("contornos inacabados").
} 
sinuosamente hacia los cuartos traseros y la pata. Desde la nuca hasta la grupa la segunda mide 7 $\mathrm{cm}$ y el surco es menos profundo que el de la línea frontal, y desde la grupa hasta el extremo de la pata mide $4,5 \mathrm{~cm}$ y apenas es un raspado superficial que cruza la línea naso-frontal de la cierva III.4.

Cierva trilineal (III.4): en perfil derecho. Infrapuesta a las ciervas III.2 y III.3 y menos visible que ellas.

Zoomorfo indeterminado (III.5): perfil izquierdo en posición rampante, aunque las líneas que se conservan no permiten una identificación segura. Tres pudieran pertenecer a una misma figura: lomo-grupa-cola $(43 \mathrm{~cm})$, nalga-pata $(14$ $\mathrm{cm})$ y vientre abombado $(21 \mathrm{~cm})$. Quizá pueda relacionarse también con él un trazo lineal profundo y ligeramente curvo en la zona del cuello.

En el área correspondiente al cuadro J-21, justo por encima de las rayas verticales que salen del suelo, hay trazos y rayados imprecisos. Algo más arriba, en paralelo al contorno de la huella dejada por la excavación de T1, asciende por la pared un sinfín de líneas entrecruzadas cuyos surcos están muy erosionados, cubiertos parcial o completamente por la huella de las aguas de escorrentía parietal y teñidos por una policromía natural que las hacen casi indescifrables. Las líneas III.6, III.7 y III.8 podrían ser prótomos de cierva mirando hacia la derecha, aunque con tan poca evidencia que las clasificamos únicamente como figuras probables (Fig. 5 arriba, recuadro de detalle).

\subsection{Zona IV}

Esta zona coincide con el Sector Occidental de las excavaciones arqueológicas y abarca la mayor parte de los grabados parietales de La Viña, que se extienden con concentración y conservación variables desde J-23 hasta G-26. El desplome de la pared es significativo en todo el sector, adaptándose los grabados a esa inclinación, pero la nomenclatura de los cuadros seguirá la de su lectura en el plano. A partir de T1 y hacia el oeste, la pared se va curvando, por lo que la orientación de los lienzos varía de $\mathrm{S}$ a E. En los cuadros $\mathrm{F}$ y $\mathrm{G}$ y los metros 25 a 27 la excavación llegó hasta el suelo del abrigo por lo que aquí se ve la pared entera. El tramo de los cuadros F-26 y
F-27 no tiene grabados, pero los de los cuadros G-25 y G-26 están descubiertos por completo. En los cuadros contiguos H-25 a J-22 la excavación llegó hasta el suelo solutrense por lo que es visible una gran parte de la historia gráfica de la pared, aunque quizá no toda. La falta de grabados en casi $1 \mathrm{~m}$ de pared entre H-25 e I-25 con toda probabilidad se debe a la fracturación y descamación de la misma. La mayor concentración se encuentra entonces en el sector de los cuadros I-24 y J-24. La pared de J-23 y J-22, aledaña a T1 y en parte coincidente con el lienzo al que se adosaba la masa de concreción excavada, sufre también una disminución drástica de grafismos.

Aquí se documentan muy bien los dos horizontes gráficos y su solapamiento es más claro. El H1 se desarrolla entre $-1,35 \mathrm{~m}$ y $-2,42 \mathrm{~m}$ de altura, respecto al nivel 0 arqueológico (correspondientes, respectivamente, a las coordenadas $Z=292,03 \mathrm{~m}$ y $290,96 \mathrm{~m})$ y el H2 entre $-0,45 \mathrm{~m}$ y $-1,68 \mathrm{~m}(\mathrm{Z}=292,93 \mathrm{~m}$ y $291,70 \mathrm{~m}$, respectivamente), por lo que en esta zona hay una coincidencia espacial entre ambos horizontes entre los puntos $-1,35 \mathrm{~m}$ y $-1,68 \mathrm{~m}$. Significa esto que hay $33 \mathrm{~cm}$ verticales de pared que fueron comunes a ambos horizontes o, dicho de otro modo, que hay una banda parietal de $33 \mathrm{~cm}$ de altura donde coincidió el campo manual de los grabadores del H1 y los del H2, reiterándose, como en la Zona II, la coincidencia espacial entre los grabados más altos de la fase más antigua y los más bajos de la fase menos antigua, pero aquí con un sugestivo caso de conexión gráfica expresa.

Las líneas verticales del Primer Horizonte Gráfico se concentran en dos conjuntos: uno, a lo largo de G-26, G-25 y el primer tramo de H-25; el otro, en I-24. En J-24 y J-23 solo hay pequeños tracitos dispersos. Los límites laterales del primer conjunto están marcados por dos profundos tajos que han intervenido en los eventos de transformación geológica sufridos por la pared. El izquierdo (IV.L1, Fig. 6) de $46 \mathrm{~cm}$ favoreció la canalización de las aguas de escorrentía parietal, formándose a partir de su extremo inferior una columna de reconstrucción lito-química que ha permitido la datación ante quem del H1 (Fortea 1992a; González-Pumariega et al. 2015). El derecho (IV.L28) mide $35 \mathrm{~cm}$ y favoreció la dirección de fracturación posterior. Entre ambos hay ocho tajos más, también anchos y profundos, que superan los $20 \mathrm{~cm}$ de longitud; tres van en paralelo 
a los dos principales y los demás, en disposición vertical u oblicua, se reparten a distintas alturas con cierta dispersión en el espacio intermedio. Intercalándose entre todos, una veintena de tracitos lineales, más cortos y menos profundos, siguen la pauta organizativa marcada por los trazos mayores, algunos tendiendo a la agrupación. La yuxtaposición entre los tajos es menos estrecha que la que rige las agrupaciones de I-24 y G-14. El conjunto se sitúa entre las alturas $-1,38 \mathrm{~m}$ y $-2,42 \mathrm{~m}$ respecto al 0 arqueológico $(Z=292,00 \mathrm{~m}$ y $290,96 \mathrm{~m}$, respectivamente), aportando la cota mínima del H1 de La Viña: $-9 \mathrm{~cm}$ respecto a la cota más baja del H1 en G-14. Destacamos que la cota más alta coincide en ambos sectores en el punto $-1,38 \mathrm{~m}$.

La mayor concentración de rayas se localiza en I-24 (Fig.7). Este conjunto está formado por la secuencia ordenada de una cuarentena de tajos verticales, cinco de los cuales destacan por su longitud (entre 35 y $73 \mathrm{~cm}$ ), anchura (entre 0,5 y $1 \mathrm{~cm}$ ) y profundidad (hasta $1 \mathrm{~cm}$ ). Como en G-14, entre los trazos más fuertes se alternan rítmicamente otros más cortos y menos profundos. Algunos están afectados por fracturas de la pared y el central (IV.L14) favoreció la línea de fracturación. El conjunto se sitúa entre las alturas $-1,35 \mathrm{~m}$ y $-2,35 \mathrm{~m}(\mathrm{Z}=292,03$ y 291,03 , respectivamente), coincidiendo casi esta última con el suelo arqueológico (IV.L18). La cota superior (IV. L11) es la más alta del H1 de La Viña, aunque solo está a $3 \mathrm{~cm}$ por encima de la de los conjuntos de G-26 y G-14.

A la altura a la que se grabó el Segundo Horizonte Gráfico la pared está muy deteriora$\mathrm{da}$, habiéndose perdido gran parte del contenido. Excepto un prótomo de cierva (IV.1, Fig. 6), la totalidad de los grabados se conserva en el sector que abarca desde I-25 hasta J-23 (Fig. 7), fundamentalmente en los dos cuadros intermedios (I-24 y J-24). Distinguimos 28 figuras: 27 ciervas (18 seguras y 9 probables) y 1 caballo.

El grueso del conjunto es un laberinto de líneas entrecruzadas anchas y profundas, idéntico al de la cornisa y los frisos de La Lluera I, donde se camuflan representaciones de ciervas (Fortea y Rodríguez 2007). Su límite izquierdo entra en el cuadro I-25 y el derecho está en el cuadro J-23; el superior alcanza la cota $-0,45 \mathrm{~m}$, en J-24 (González-Pumariega et al. 2015: figs. 5 y 7). La base de esta maraña de trazos está delimitada por el borde superior, casi horizontal (cota en torno a $-1,35 \mathrm{~m}$ ) de una oquedad cuadrangular. Bajo esta arista, en otro plano de la pared un poco retranqueado, se extiende el campo gráfico ocupado por los tajos del H1. Al lado o por encima del extremo superior de esas rayas, se individualizan el caballo IV.2 y la cierva IV.3. Es aquí donde se solapan expresamente los dos horizontes.

Prótomo de cierva (IV.1): es la figura más occidental del yacimiento, en perfil derecho, mirando ligeramente hacia arriba, con la característica convención trilineal. La boca está situada a $-1,27 \mathrm{~m}$ y el extremo inferior de la línea del pecho a $-1,36$ $\mathrm{m}$, solo a $2 \mathrm{~cm}$ por encima del extremo superior del tajo vertical grabado aquí a más altura.

Caballo (IV.2): orientado hacia la izquierda. Muestra el estereotipo característico del Nalón: curva cérvico-dorsal muy sinuosa en forma de cuello de cisne, cuartos traseros anchos, vientre abultado con indicación neta del sexo, línea pectoral suavemente convexa y dos patas; la delantera tiende a la forma de $\mathrm{V}$ pero abierta en el extremo y la trasera se cierra en extremo curvo. La cabeza ha desaparecido por la rotura de la pared, aunque tres líneas en esquema rectangular quizá correspondan al morro (como en los caballos de La Lluera I). Mide 32 x $28 \mathrm{~cm}$. Se superpone a tres de los tajos verticales del H1, cortando en seco (abruptamente) a dos de ellos: uno con el pecho (IV.L29) y otro con el vientre (IV.L15); reutiliza, sin embargo, el tercero (IV. L14), trazando a partir de su extremo superior la cara anterior de la pata delantera. La unión entre las líneas de ambos horizontes es aquí precisa y cuidadosa, recurriendo a una solución gráfica que resuelve con ingenio la eventualidad del lienzo previamente utilizado. Esta figura es la de menor cota de todas las del H2 de La Viña: el enlace entre la pata y el extremo del tajo vertical se produce, respecto al 0 arqueológico, a $-1,68$ $\mathrm{m}$ y la parte superior de la crinera (punto más alto del caballo) está a $-1,46 \mathrm{~m}$; así, toda la representación está en el campo manual del H1. Según las estimaciones hechas sobre las alturas del campo manual (González-Pumariega et al. 2015), la relación entre esta figura de caballo y una persona de $1,75 \mathrm{~m}$ de estatura situada en los distintos suelos de ocupación, sería como sigue: desde el nivel XI (Auriñaciense reciente), las patas del caballo le quedarían a la altura de los ojos; desde el nivel VII (Gravetiense final: Fortea 
1992a; Martínez 2015), las patas le quedarían a la altura del pecho; desde el nivel VI (Solutrense medio), la cabeza del caballo estaría, más o menos, a $1 \mathrm{~m}$ del suelo.

Cierva (IV.3): prótomo en perfil derecho. Es una figura poco habilidosa aunque suficientemente identificable como cierva. Está grabada algo más arriba que el caballo IV.2 y situada inmediatamente a la izquierda del tercio superior del tajo vertical IV.L11.

Cierva (IV.4): trilineal en perfil derecho; un tracito sugiere la comisura de la boca. La base del cuello se apoya sobre el borde fracturado de la pared que describimos más arriba como límite inferior del friso de trazos enmarañados. Esta expresiva cabecita, aun estando rodeada de trazos lineales ya indeterminados, está bien singularizada.

Ciervas superpuestas (IV.5 y IV.6): dos claros prótomos en perfil derecho con distinta dirección. La cierva infrapuesta (IV.5) se representa con dos orejas, mediante la prolongación habitual de la línea naso-frontal, pero también de la cervical, alargada voluntariamente y cruzando a la anterior. Como las ciervas III.1 y III.2, la línea de la espalda no se traza recta sino en ángulo, diferenciando la nuca del resto. La cierva superpuesta (IV.6) está grabada un poco más alta que la primera y es más expresiva porque tiene la boca abierta: los extremos de las líneas frontal y del cuello no se tocan y se aprovecha el microrrelieve de la pared para reforzar esta expresión. La coincidencia espacial que se establece entre estas dos ciervas es diferente a la infinidad de cruces, superposiciones y reutilizaciones de líneas que hay en el resto del friso enmarañado; aquí, la relación estratigráfica solo afecta a dos figuras bien diferenciadas en el lienzo, estableciéndose una composición de emparejamiento paralelo, en vez de opuesto o cruzado como en el Friso Posterior de La Lluera I (Fortea y Rodríguez 2007: 176), pero que también sugiere una perspectiva espacial entre ambas.

Por último, hacia la mitad inferior de la línea naso-frontal de la cierva IV.5, hay un tracito oblicuo que parece sugerir la presencia de otra cierva (IV.7) porque equivale a la nuca, reaprovechando las líneas frontal y pectoral de la previa. También está en perfil derecho.

En el enredo de trazos que afecta al resto de la pared de este sector, hasta el día en que dimos por cerrado este artículo, hemos leído exclusiva- mente ciervas. La mayoría son seguras $(\mathrm{N}=13)$, aunque otras las consideramos probables bien por el deterioro del soporte, bien porque los numerosos cruces de líneas podrían inducir a error $(\mathrm{N}=5)$ o bien porque son acéfalas $(\mathrm{N}=3)$. $\mathrm{La}$ totalidad están representadas en perfil derecho. Así, en la maraña de trazos del área del cuadro I-25 distinguimos 1 cierva segura, en posición rampante (IV.8) y 1 probable (IV.9). En el cuadro I-24, localizamos 4 seguras (IV.10, IV.13, IV.15 y IV.16) y 3 probables (IV.11, IV.12, IV.14) y en el cuadro J-24, 8 seguras (IV.18, IV.19, IV.20, IV.21, IV.23, IV.24, IV.26 y IV.27), 1 probable (IV.28) y 3 acéfalas (IV.17, IV.22 y IV.25). Las ciervas IV.25 a IV.28 son confusas pues sus superposiciones y aprovechamientos paralelos, no cruzados, dificultan la comprensión temporal de la secuencia.

La representación en perfil derecho de las ciervas, localizadas en esta Zona IV, con independencia de su posición horizontal, oblicua o vertical contrasta con la del caballo en perfil izquierdo (Tab. 1). Las de mayor tamaño también son las de surco más profundo, superponiéndose (imponiéndose) a todas las demás. Esto pudiera sugerir que, ante la apretada acumulación de trazos en un mismo campo gráfico, al último grabador no le quedara más alternativa para hacer visible y/o posible su intervención que ampliar la escala de sus obras y profundizar el surco.

\begin{tabular}{|l|c|c|c|c|c|c|c|c|}
\cline { 2 - 9 } \multicolumn{1}{c|}{} & \multicolumn{2}{c|}{ Zona I } & \multicolumn{2}{c|}{ Zona II } & \multicolumn{2}{|c|}{ Zona III } & \multicolumn{2}{c|}{ Zona IV } \\
\cline { 2 - 9 } \multicolumn{1}{c|}{} & $\boldsymbol{D}$ & $\boldsymbol{I}$ & $\boldsymbol{D}$ & $\boldsymbol{I}$ & $\boldsymbol{D}$ & $\boldsymbol{I}$ & $\boldsymbol{D}$ & $\boldsymbol{I}$ \\
\hline Cierva & 1 & 1 & 2 & 1 & 4 & 3 & 27 & \\
\hline Caballo & & & & & & & & 1 \\
\hline Bisonte & & & & 1 & & & & \\
\hline $\begin{array}{l}\text { Zoomorfo } \\
\text { indet. }\end{array}$ & 1 & & & & & 1 & & \\
\hline
\end{tabular}

Tab. 1. Abrigo de La Viña. Orientación de los perfiles de las representaciones figurativas: $D$ derecho; $I$ izquierdo.

\section{COMENTARIOS A LOS GRABADOS FIGURATIVOS}

La discriminación de elementos figurativos entre el sinfín de líneas es tarea ardua. Además, la luz natural condiciona relativamente la lectura a 
lo largo del día, observación que ya anotamos al referirnos a los grabados de La Lluera I (González-Pumariega 2008). A la dificultad de lectura, intrínseca al desorden gráfico, se añade el suavizado de las formas (provocado por la erosión de los surcos) y el extenso clasticismo de la pared, que en algunos casos impide corroborar ciertas intuiciones.

Ciñéndonos a lo conservado, este palimpsesto se construye fundamentalmente con ciervas, motivo que abarrota el espacio gráfico. A partir de elementos preexistentes, se prolongan, añaden $\mathrm{y}$ profundizan trazos, generando nuevos motivos. Aunque dentro del laberinto hay ciervas incuestionables, el constante cruce de líneas contribuye a la creación de formas secundarias que, en ocasiones, invitan a ser leídas como esas figuras o como otras diferentes, aunque con sombra de incertidumbre para el observador. En este sentido, hemos seleccionado algunas (aquellas que clasificamos como probables) y descartado otras, primando aquellos datos que consideramos favorecen la objetividad en la observación: la homogeneidad formal del trazo (anchura y profundidad), el sentido de su continuidad o interrupción, la escala de la figura y, obviamente, la adaptación al estereotipo formal. Así, más que dejar cerrada la labor de documentación con este trabajo, hemos fijado una pausa, pues al igual que ocurre en La Lluera I y II, cada acercamiento que se hace a la pared es susceptible de incrementar el número de representaciones.

Como en los demás abrigos de la cuenca media del Nalón, en La Viña se representa mayoritariamente la cierva. Aparece, de manera más o menos expresa o con mayor o menor grado de conservación, en todas las zonas. En las Zonas I, II y III se orientan tanto a la derecha $(\mathrm{N}=7)$ como a la izquierda $(\mathrm{N}=5)$, pero en la Zona IV solo hemos reconocido la orientación hacia la derecha. Como en La Lluera I, la cierva, formalmente muy estereotipada, recibe en La Viña una tratamiento gráfico dispar, pues algunas se individualizan y otras están emboscadas entre incontables trazos. A veces, los continuos cruces de líneas confunden la representación de las orejas. Casi todas se adaptan a la definición trilineal clásica (tres líneas que solo se tocan -no se cortan- y, por tanto, representan una sola oreja), pero al menos la IV.5 plantea con seguridad otra alternativa, también trilineal pero con cruce deliberado entre la naso-frontal y la cervical, representando esquematizadamente las dos orejas. En 3 de las 39 ciervas se representa la boca, ya sea mediante la separación de las líneas frontal y mandibular (IV.6), ya sea añadiendo un tracito independiente (IV.4), incluso mediante ambos recursos (III.2). Se aproximan a la morfología de la cierva casi todas las anatomías acéfalas que, bien por deterioro del soporte o por indefinición formal, quedan reducidas a las líneas del lomo y del pecho.

Al patente dominio de la cierva en La Viña $(90,7 \%)$ se une la representación de un caballo y la de un bisonte. El primero compite en protagonismo con la cierva por su tamaño y su singularidad espacial. El bisonte lo reconocemos con cierta dificultad, aunque no deja de ser sugerente que un tema tan mal representado en La Viña sea el que aparezca a menos de $2 \mathrm{~km}$ de distancia, aguas abajo del Nalón, en el abrigo de Los Murciélagos (Fortea 1981) (Tab. 2).

\begin{tabular}{|l|c|c|c|c|c|}
\cline { 2 - 6 } \multicolumn{1}{c|}{} & Zona I & Zona II & Zona III & Zona IV & TOTAL \\
\hline Cierva & $(2)$ & 3 & $4(3)$ & $19(8)$ & $26(13)$ \\
\hline Caballo & & & & 1 & 1 \\
\hline Bisonte & & 1 & & & 1 \\
\hline $\begin{array}{l}\text { Zoomorfo } \\
\text { indet. }\end{array}$ & 1 & & 1 & & 2 \\
\hline TOTAL & $1(2)$ & 4 & $5(3)$ & $20(8)$ & $30(13)$ \\
\hline
\end{tabular}

Tab. 2. Abrigo de La Viña. Cómputo de las representaciones figurativas. Entre paréntesis las consideradas probables.

Por último, como ya indicara Fortea (1994), algunas áreas rojizas del frente parietal son debidas a teñidos naturales y se identifican bien en relación con las aguas de escorrentía parietal. Sin embargo, aquí y allá, en el ámbito del H2 de las Zonas III y IV hemos reconocido manchitas de ocre rojo que asociamos con aplicaciones de este pigmento sobre la pared, aunque son indicios tan escasos y reducidos que no permiten valorar su verdadero alcance. No deja de ser atractiva la hipótesis de suponer el repaso de los surcos con color rojo (Fortea 1990a; Fortea y Rodríguez 2007), para realzar las líneas grabadas, evidenciar figuras escondidas o reavivar su significado o, simplemente, como alternativa a la imposibilidad de añadir más grabados sobre un campo gráfico completamente saturado. 


\section{LOS DOS HORIZONTES GRÁFICOS DEL NALÓN EN LA VIÑA. ATRIBUCIÓN CULTURAL}

Resumiremos la cronología de ambos horizontes al haber sido ya publicada (Fortea 1994; 2000-2001; 2005-2006; González-Pumariega et al. 2015). Aunque se trate de una cuestión que "sigue abierta" (González Sainz et al. 2013: 393) y "susceptible de mayores precisiones" (Fortea y Rodríguez 2007: 191), los argumentos arqueológicos y relativos al campo manual indican que el H1 se grabó durante el Auriñaciense y el H2, acaso a partir del Gravetiense pero, sobre todo, durante el Solutrense. Dado el marcado contraste formal y las divergencias conceptual y temática entre ambos conjuntos, así como su diferente posición en altura, creemos que la expresión "horizonte gráfico", acuñada por Fortea, responde acertadamente a una diacronía cultural en el dispositivo gráfico de La Viña. Es difícil atribuir al $\mathrm{H} 1$ cualquiera de las figuras animales que, singularizadas en la parte más baja del $\mathrm{H} 2$, coinciden espacialmente con él.

Fortea parecía entender las rayas del H1 con un cierto sentido diacrónico, al apuntar que podían haber sido grabadas desde distintos suelos auriñacienses ("incluso los más antiguos", Fortea 2000-2001: 178), pero la coherente organización interna del conjunto, su rítmica yuxtaposición y su extensión en distintas agrupaciones a lo largo de la pared, parece responder mejor a actos no demasiado dilatados en el tiempo. Hacia ello apuntan también la excesiva altura a la que se encontraría la cota superior del horizonte respecto a los suelos auriñacienses más antiguos (González-Pumariega et al. 2015) y la progresiva configuración del suelo del asentamiento, cuya superficie no se enrasó hasta el Auriñaciense reciente.

El H1 se extiende desde la Zona II a la IV de forma organizada y uniforme $\mathrm{y}$, aun con distinto grado de concentración, probablemente con continuidad (Zona III). Las cotas superior e inferior de las líneas que lo configuran son muy similares a lo largo del frente parietal, siendo los límites superior e inferior del conjunto casi horizontales, sin que el grado de inclinación del suelo corresponda exactamente con el del dispositivo gráfico (González-Pumariega et al. 2014). Esta regularización compositiva plantea una posible homogeneización intencional por sus autores y, en cualquier caso, requeriría una visión global de la pared. Todo parece indicar que su uso como campo de expresión gráfica se dio a partir de los suelos que constituyeron, desde el Sector Central al Occidental, un mismo horizonte de ocupación del abrigo, esto es, a partir del Auriñaciense reciente. Es decir, los primeros auriñacienses que se asentaron en La Viña no habrían utilizado la pared como campo de expresión simbólica.

Ratificamos las conclusiones expresadas por Fortea sobre el carácter esencialmente solutrense del H2 de La Viña, aunque sin poder descartar la participación de algunos gravetienses, sobre todo en las representaciones figurativas situadas en la cota más baja. Sin otros métodos de datación numérica, absoluta o relativa (que en muchos casos están aportando al arte rupestre más alboroto que desenlaces), la información arqueológica aportada por este yacimiento y por La Lluera I (Rodríguez et al. 2012) sigue siendo el marco cronológico de referencia para los grabados exteriores de este horizonte en la cuenca media del Nalón. Los paralelos situados fuera del ámbito geográfico inmediato (Chufín, Venta de la Perra, Hornos de la Peña) no han rebatido sustancialmente lo conocido hasta ahora.

\section{CONCLUSIONES}

El abrigo de La Viña es el yacimiento más importante del valle medio del Nalón por su amplia secuencia arqueológica. Su gran frente parietal conserva además un significativo conjunto de grabados parietales, si bien su conservación se ha visto muy condicionada por su fuerte exposición a la intemperie. Con todo, su excepcionalidad queda avalada por ser el único de los abrigos y cuevas del Nalón donde coexisten los dos horizontes artísticos reconocidos en este contexto geográfico $\mathrm{y}$, además, parcialmente cubiertos por la estratigrafía.

El H1 se plasma aquí de forma tan categórica que podría considerarse un unicum, atribuible al Auriñaciense reciente. No tiene paralelo igual en ningún otro yacimiento cantábrico, aunque los grabados lineales no figurativos de la cueva de El Conde puedan entenderse como su versión reducida, adaptados a un contexto espacial 
y parietal de dimensiones mucho menores y respondiendo en un mismo sentido cronológico (Fortea 2000-2001).

La Viña no es el caso más completo del H2 pero repite las características de los otros doce sitios del Nalón donde también se documenta (Fortea 2005-2006; Fortea y Rodríguez 2007; González-Pumariega et al. 2015), tanto en la versión más desahogada como en la más laberíntica con un claro dominio temático de la cierva y la presencia más minoritaria del caballo y el bisonte, así como el juego testimonial de los signos en V. No se puede descartar el papel gravetiense de algunas representaciones figurativas, pero entendemos que el conjunto tiende sobre todo hacia el solutrense $y$, atendiendo a la figura I.1, ni siquiera podemos descartar intervenciones posteriores. En todo caso, los grabados profundos exteriores de La Viña responden con coherencia a la fuerte unidad interna que tal modalidad gráfica manifiesta en este territorio cultural situado, en palabras de Fortea, en el lejano occidente cantábrico.

\section{AGRADECIMIENTOS}

A Javier Fortea, in memoriam. A los miembros del equipo de excavación e investigación de La Viña; a Sergio Ríos González y Manuel Mallo Viesca por las fotografías y a José Luis Seoane Moro (Uniovi) por la ayuda prestada. Agradecemos los comentarios de G. Sauvet, C. González Sainz y D. Gárate sobre la figura I.1, así como las consideraciones remitidas por los evaluadores.

\section{BIBLIOGRAFÍA}

Aguirre, M. y González Sainz, C. 2011: "Placa con grabado figurativo del Gravetiense de Antoliñako koba (Gautegiz-Arteaga, Bizcaia)". Kobie 30: 43-62.

Barandiarán, I.; Fortea; J. y Hoyos, M. 1996: “El Auriñaciense tardío y los orígenes del Gravetiense: el caso de la Región Cantábrica". En A. Montet-White y A. Palma di Cesnola (eds.): XIII International Congress Union Internationale des Sciences Préhistoriques et Protohistoriques (Forli 1996) Coll. XIXII: 263-293. Forlì.

Corchón, M. S. 2014: "Los orígenes del arte parietal paleolítico en Asturias: el valle del Nalón como mo- delo". En M. A. de Blas Cortina (ed.): Expresión simbólica y territorial: los cursos fluviales y el arte paleolítico en Asturias. Real Instituto de Estudios Asturianos. Oviedo: 13-63.

Corchón, M. S.; Fano, M. A.; Gárate, D.; García-Moreno, A.; Rivero, O. y Ortega, P. 2014: "La ocupación del Valle del Nalón durante el periodo 13,2-11,5 ky BP: el contexto magdaleniense de la Peña de Candamo". En M. S. Corchón y M. Menéndez (eds.): Cien años de arte rupestre 25 paleolítico: centenario del descubrimiento de la cueva de la Peña de Candamo, 1914-2014. Ediciones Universidad de Salamanca. Salamanca: 221-244.

Fortea, J. 1981: "Investigaciones en la cuenca media del Nalón (Asturias, España). Noticia y primeros resultados". Zephyrus XXXII-XXXIII: 5-16.

Fortea, J. 1983: "Perfiles recortados del Nalón medio (Asturias)". Homenaje al Profesor Martín Almagro Basch, I. Ministerio de Cultura. Madrid: 343-353.

Fortea, J. 1990a: "Abrigo de La Viña. Informe de las campañas 1980-1986". Excavaciones Arqueológicas en Asturias 1983-1986 1: 55-68.

Fortea, J. 1990b: "El arte paleolítico en Asturias". En F. J. Fernández Conde (ed.): Historia de Asturias, I. Prehistoria-Historia Antigua. Prensa Asturiana. Oviedo: 65-84.

Fortea, J. 1990c: "Préface". Bulletin de la Société Préhistorique Ariège-Pyrénées XLV: 5-10.

Fortea, J. 1992a: "Abrigo de La Viña. Informe de las campañas 1987-1990". Excavaciones Arqueológicas en Asturias 1987-1990 2: 19-28.

Fortea, J. 1992b: "Abrigo de La Viña (Asturias)". En La naissance de l'Art en Europe. Unión Latina. París: 255-256.

Fortea, J. 1994: “Los 'santuarios' exteriores en el Paleolítico Cantábrico”. Complutum 5: 203-220.

Fortea, J. 1995: "Abrigo de La Viña. Informe y primera valoración de las campañas 1991 a 1994". Excavaciones Arqueológicas en Asturias 1991-1994 3: $19-32$.

Fortea, J. 1996: "Pintura Paleolítica". En J. Barón (ed.): El Arte en Asturias a través de sus obras. Prensa Asturiana. Oviedo: 693-708.26

Fortea, J. 1999: “Abrigo de La Viña. Informe y primera valoración de las campañas de 1995 a 1998". Excavaciones Arqueológicas en Asturias 1995-1998, 4: 31-41.

Fortea, J. 2000-2001: “Los comienzos del arte paleolítico en Asturias: aportaciones desde una arqueología contextual no postestilística". Zephyrus LIII-LIV: $177-216$.

Fortea, J. 2001: “El Paleolítico superior en Galicia y Asturias (1996-2000)". En P. Noiret (ed.): Le Paléolithique supérieur européen. Bilan quinquennal 1996-2001. Etudes et Recherches Archéologiques de l’Université de Liège 97. Liège: 149-160.

Fortea, J. 2003. "L'art rupestre paléolithique dans la péninsule ibérique. Découvertes récentes, géogra- 
phie et chronologie". En R. Desbrosse y A. Thévenin (eds.): Préhistoire de l'Europe: des origines à l'Âge du Bronze. 125 Congrès national des Sociétés historiques et scientifiques (Lille 2000). Éditions du CTHS. Paris: 95-108.

Fortea, J. 2005: "La plus ancienne production artistique du Paléolitique ibérique". Simposio Pitture paleolitiche nelle Prealpi venete. Grotta di Fumane e Riparo Dalmieri (Verona 2003). Preistoria Alpina, $\mathrm{n}^{\circ}$ speciale: $53-65$.

Fortea, J. 2005-2006: "Los grabados exteriores de Santo Adriano (Tuñón. Santo Adriano. Asturias)". Munibe, 57: 5-34.

Fortea, J. y Rodríguez, V. 2007. "Los grabados exteriores de la cuenca media del Nalón". En J. Rodríguez (ed.): La Prehistoria en Asturias: un legado artístico único en el mundo. Prensa Asturiana. Oviedo: 167-194.

González-Pumariega, M. 2008: Guía del arte rupestre paleolítico en Asturias. Ménsula. Pola de Siero.

González-Pumariega, M. 2014: "El arte rupestre paleolítico del abrigo de La Viña (Oviedo, Asturias). Presentación de su estudio actual dentro del proyecto de investigación del yacimiento". En M. A. Medina-Alcaide, A. J. Romero Alonso, R. M. RuizMárquez y J. L. Sanchidrián Torti (eds.): Sobre rocas y huesos: las sociedades prehistóricas y sus manifestaciones plásticas. Universidad de Córdoba y Fundación Cueva de Nerja. Córdoba: 84-95.

González-Pumariega, M.; Rasilla, M. de la; Santamaría, D.; Duarte, E. y Santos, G. 2014: "Relación entre la estratigrafía y los grabados parietales del primer horizonte gráfico del Abrigo de La Viña (La Manzaneda, Oviedo, Asturias)". En M. S. Corchón y M. Menéndez (eds.): Cien años de arte rupestre paleolítico: centenario del descubrimiento de la cueva de la Peña de Candamo, 1914-2014. Ediciones Universidad de Salamanca. Salamanca: 351-357.

González-Pumariega, M.; Rasilla, M. de la; Santamaría, D.; Duarte, E. y Santos, G. 2015: "La Viña rock shelter (La Manzaneda, Oviedo, Asturias): relation between stratigraphy and parietal engravings". Quaternary International http://dx.doi.org/10.1016/j. quaint.2015.07.011

González Sainz, C. 1999: "Sobre la organización cronológica de las manifestaciones gráficas del paleolítico superior. Perplejidades y algunos apuntes desde la región cantábrica". Edades, Revista de Historia 6: $123-144$.

González Sainz, C.; Ruiz Redondo, A. y González Morales, M. 2013: "Manifestaciones parietales paleolíticas de la cueva de El Molín y del abrigo de Entrefoces (La Foz de Morcín, Asturias)". En M. de la Rasilla (ed.): F. Javier Fortea Pérez, Universitatis Ovetensis Magister. Universidad de Oviedo y Ménsula. Oviedo: 375-399.

Leroi-Gourhan, A. 1971: Préhistoire de l'art occidental. Ed. L. Mazenod, París.

Martínez Fernández, L. 2015: El Gravetiense en el sector occidental cantábrico y sus conexiones pirenaicas. Servicio de Publicaciones de la Universidad de Oviedo. Oviedo. http://digibuo.uniovi.es/dspace/ handle/10651/3363528 (consulta 12-I-2016).

Rodríguez, J. A.; Barrera, J. M. y Aguilar, E. 2012: "Cueva de La Lluera I (San Juan de Priorio, Oviedo, Asturias, España): estratigrafía solutrense". Espacio, Tiempo y Forma 5: 235-248.

Santamaría, D. 2012: La transición del Paleolítico Medio al Superior en Asturias. El abrigo de La Viña (La Manzaneda, Oviedo) y la Cueva de El Sidrón (Borines, Piloña). Servicio de Publicaciones de la Universidad de Oviedo. Oviedo. http://hdl.handle. net/10651/19328 (consulta 10-XII-2015).

Santamaría, D.; Duarte, E.; González-Pumariega, M.; Martínez, L.; Suárez, P.; Fernández de la Vega, J.; Santos, G.; Higham, T.; Wood, R. y Rasilla, M. de la 2014: "La Viña". En R. Sala, E. Carbonell, J. M. Bermúdez de Castro y J. L. Arsuaga (eds.): Los cazadores recolectores del Pleistoceno y del Holoceno en Iberia y el estrecho de Gibraltar. Universidad de Burgos y Fundación Atapuerca. Burgos: 95-99. 